\title{
Estructuras del líder
}

Gómez Radioboy, Rubén

rubengomezradioboy@outlook.com

DIBUJOS DE ARQUITECTURA 


\section{Cuaderno de proyecto}

«Estructuras del lider» (2016)

Rubén Gómez «Radioboy» 
Índice:

- Descripción del proyecto

- Proyecto

- «Estructuras del lider 1»

- «Escena eliminada de Estructuras del triste (2014)» (Fotograma) 13

- «Mortinta aglo»

- Datos del autor y agradecimientos 
La aparentemente beneficiosa sofisticación de nuestros métodos de supervivencia nos está llevando a la extinción inminente de la especie. Esto no sucede en ninguna otra especie perteneciente a lo que ahora inocentemente denominamos como dominios archaea (1), bacteria y eukarya (2). Es decir, todas las formas de vida conocidas en la Tierra.

El cortometraje «Estructuras del triste» (2014) nació como una esperanza para resurgir desde esta decadencia. El ser humano había obrado contra la verdad y ahora se apartaba de una vida de mentiras para volver al pasado, libre de actitudes malévolas, al principio con resignación, para darse cuenta finalmente de que estaba volviendo a ser humano de nuevo, organismo de nuevo, vacío de nuevo.

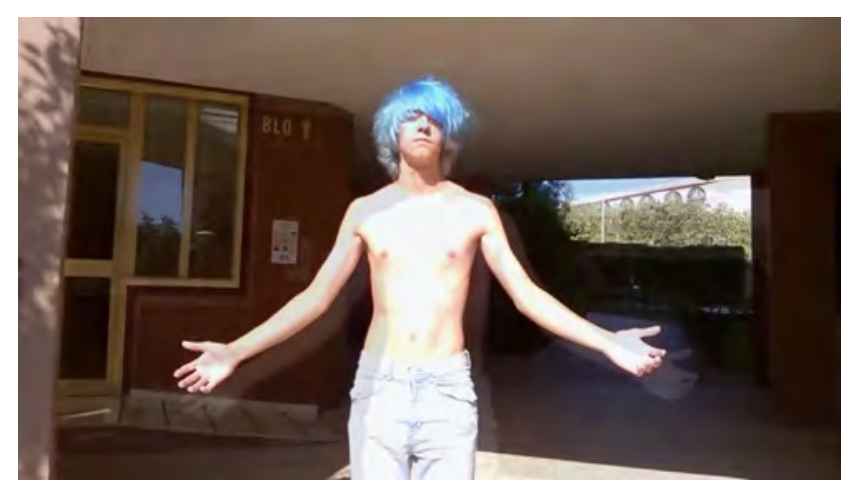

«Estructuras del triste» (2014) (Fotograma de vídeo) Vídeo, Rubén Gómez «Radioboy»

«Estructuras del líder» (2016) habla de lo fácil que es olvidar cómo hemos llegado a descubrir la verdad una vez que nuestro entorno nos invita eufóricamente a seguir viviendo en la mentira.

El proyecto consiste en tres piezas.

- «Estructuras del lider 1»:

Ocho imágenes de narrativa lineal reescribiendo escena a escena el cortometraje.

- «Escena eliminada de Estructuras del triste (2014)»:

Vídeo mostrando una escena eliminada del cortometraje.

- «Mortinta aglo» (Águila muerta en esperanto):

El águila que aparece en el cortometraje ha muerto.

(1) Las arqueas (Archaea, Et: del griego ápxaĩa arkhaía: las antiguas) son un grupo de microorganismos unicelulares que al igual que las bacterias, son de morfología procariota (sin núcleo ni, en general, orgánulos membranosos internos), pero que son fundamentalmente diferentes a éstas, de tal manera que conforman su propio dominio o reino. Fuente: Wikipedia.

(2) Eukaryota, Eukarya o Eucaria (palabras con etimología del griego: عũ eu —-bueno', 'bien'- y kápuov karyon —-'nuez', 'carozo', 'núcleo'-) es el dominio (o imperio) que incluye los organismos formados por células con núcleo verdadero. Estos organismos constan de una o más células eucariotas, abarcando desde organismos unicelulares hasta verdaderos pluricelulares [...] Fuente: Wikipedia. 

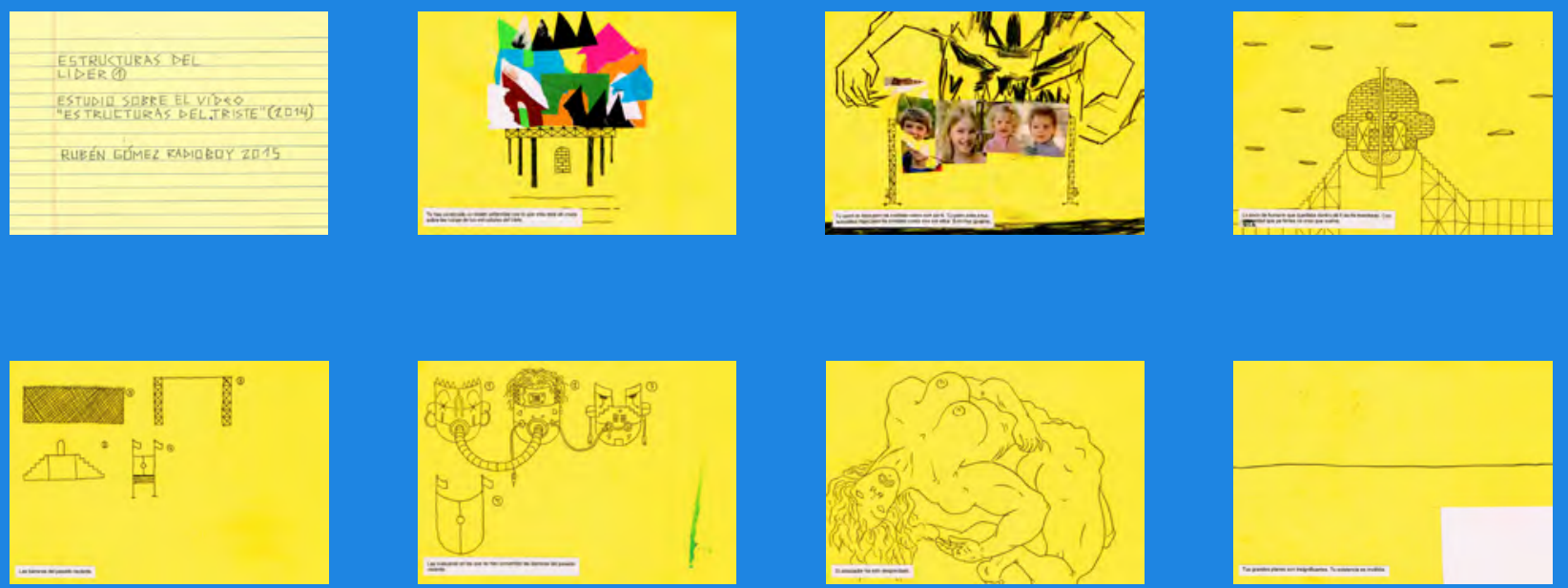

Autor: $\quad$ Rubén Gómez "Radioboy»

Título: $\quad$ "Estructuras del líder 1»

Serie: $\quad$ "Estructuras del líder»

Año:

2015

Técnica: Mixta

Soporte: $\quad$ Papel de diferentes gramajes

Dimensiones: 14,85 x 21 cm c/u 


\section{ESTRUKTURAS DEL \\ LIDER (1)}

\section{ESTUDID SOBRE EL VID $\diamond$ "ESTRULTURAS DEL,TRISTE" (2014)}

\section{RUBÉN GÚMEZ RADIDBDY ZD15}

Autor: $\quad$ Rubén Gómez «Radioboy»

Título: $\quad$ "Estructuras del líder 1» (Fragmento)

Serie: $\quad$ "Estructuras del líder»

Año: $\quad 2015$

Técnica: Lápiz 2B, bolígrafo negro de tinta líquida y fijador incoloro mate

Soporte: $\quad$ Papel amarillo con lineado horizontal de $70 \mathrm{~g} / \mathrm{m}^{2}$

Dimensiones: 14,85 x $21 \mathrm{~cm}$ 


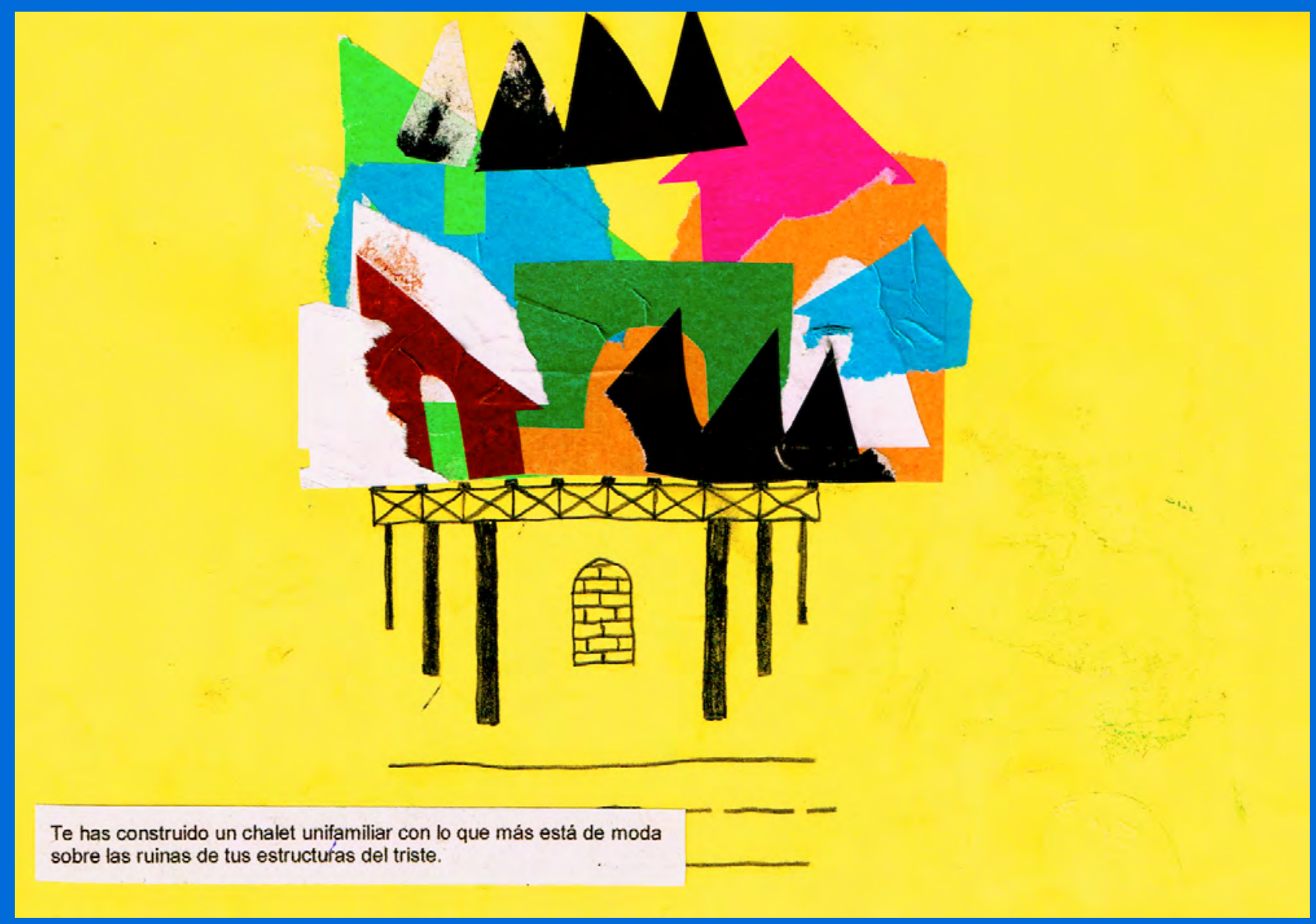

Autor: Rubén Gómez «Radioboy»

Título: $\quad$ "Estructuras del líder 1» (Fragmento)

Serie: $\quad$ "Estructuras del líder»

Año: $\quad 2015$

Técnica: Collage, lápiz 4B y fjjador incoloro mate

Soporte: $\quad$ Cartulina amarilla de $200 \mathrm{~g} / \mathrm{m}^{2}$

Dimensiones: 14,85 x $21 \mathrm{~cm}$ 


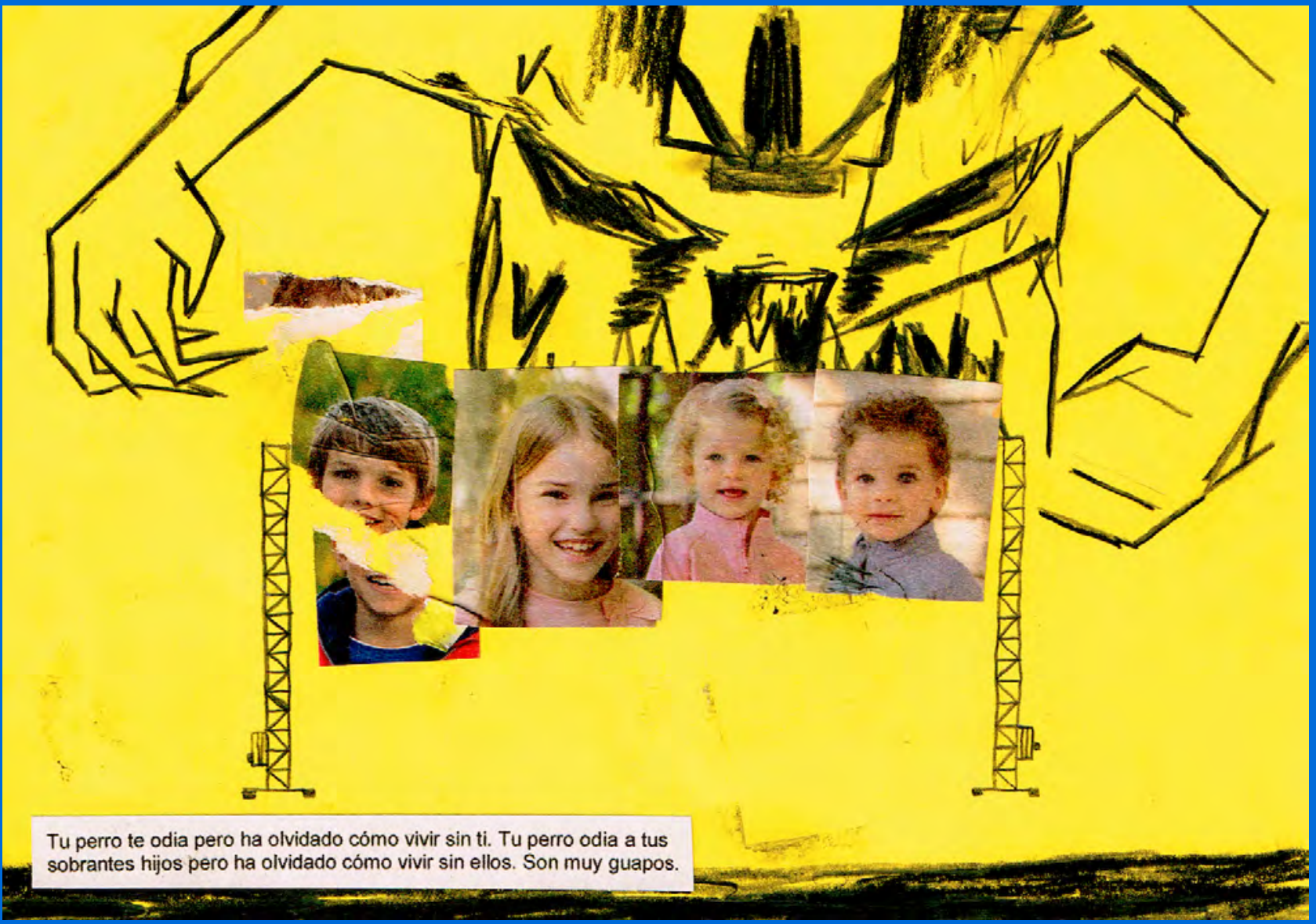

Autor: $\quad$ Rubén Gómez «Radioboy»

Título: $\quad$ "Estructuras del líder 1» (Fragmento)

Serie: $\quad$ "Estructuras del líder»

Año: $\quad 2015$

Técnica: Collage, lápiz 4B y fjjador incoloro mate

Soporte: Cartulina amarilla de $200 \mathrm{~g} / \mathrm{m}^{2}$

Dimensiones: 14,85 x $21 \mathrm{~cm}$ 


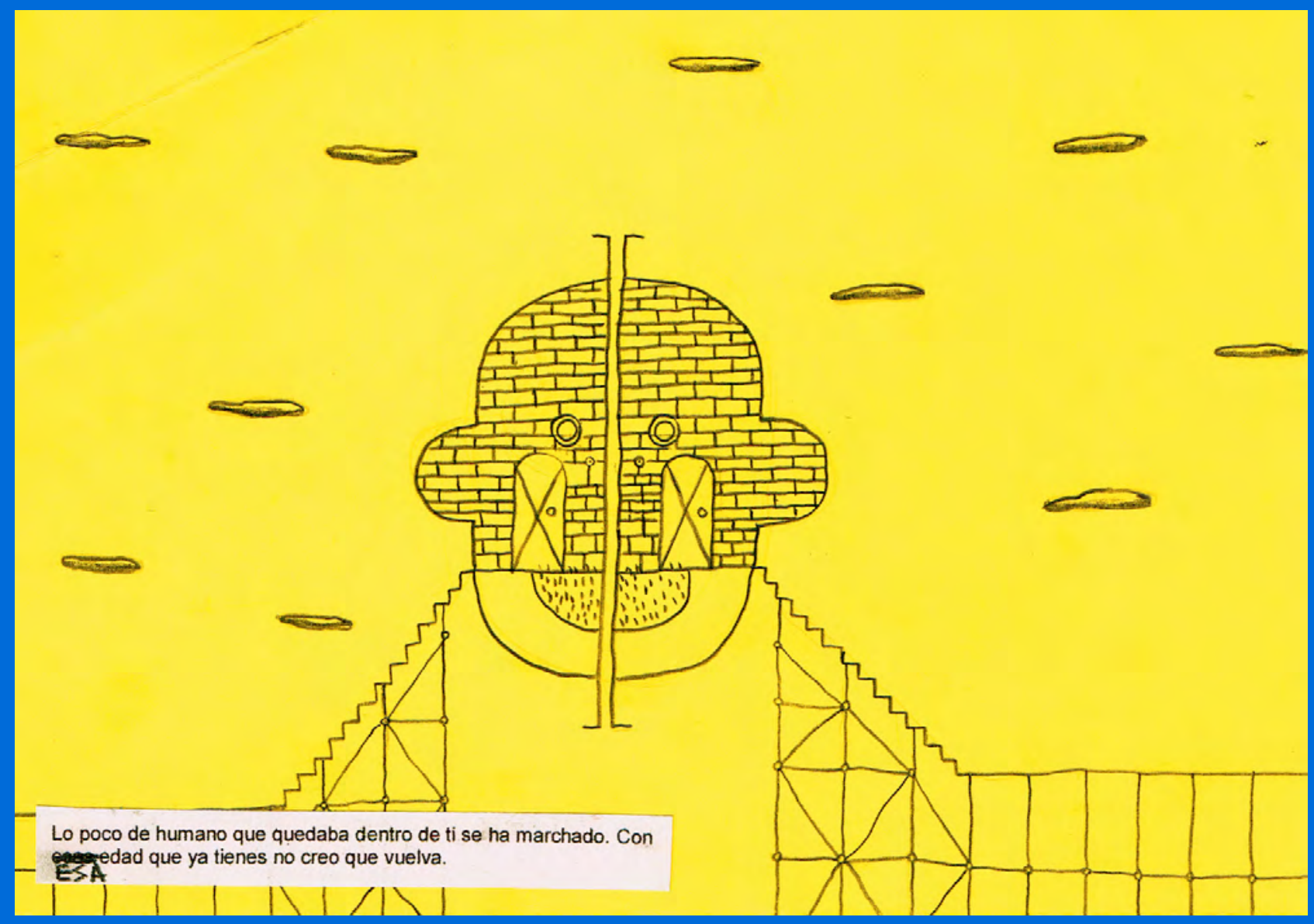

Autor: $\quad$ Rubén Gómez «Radioboy»

Título: $\quad$ "Estructuras del líder 1» (Fragmento)

Serie: $\quad$ "Estructuras del líder»

Año: $\quad 2015$

Técnica: Collage, lápiz 4B y fjjador incoloro mate

Soporte: $\quad$ Cartulina amarilla de $200 \mathrm{~g} / \mathrm{m}^{2}$

Dimensiones: 14,85 x $21 \mathrm{~cm}$ 


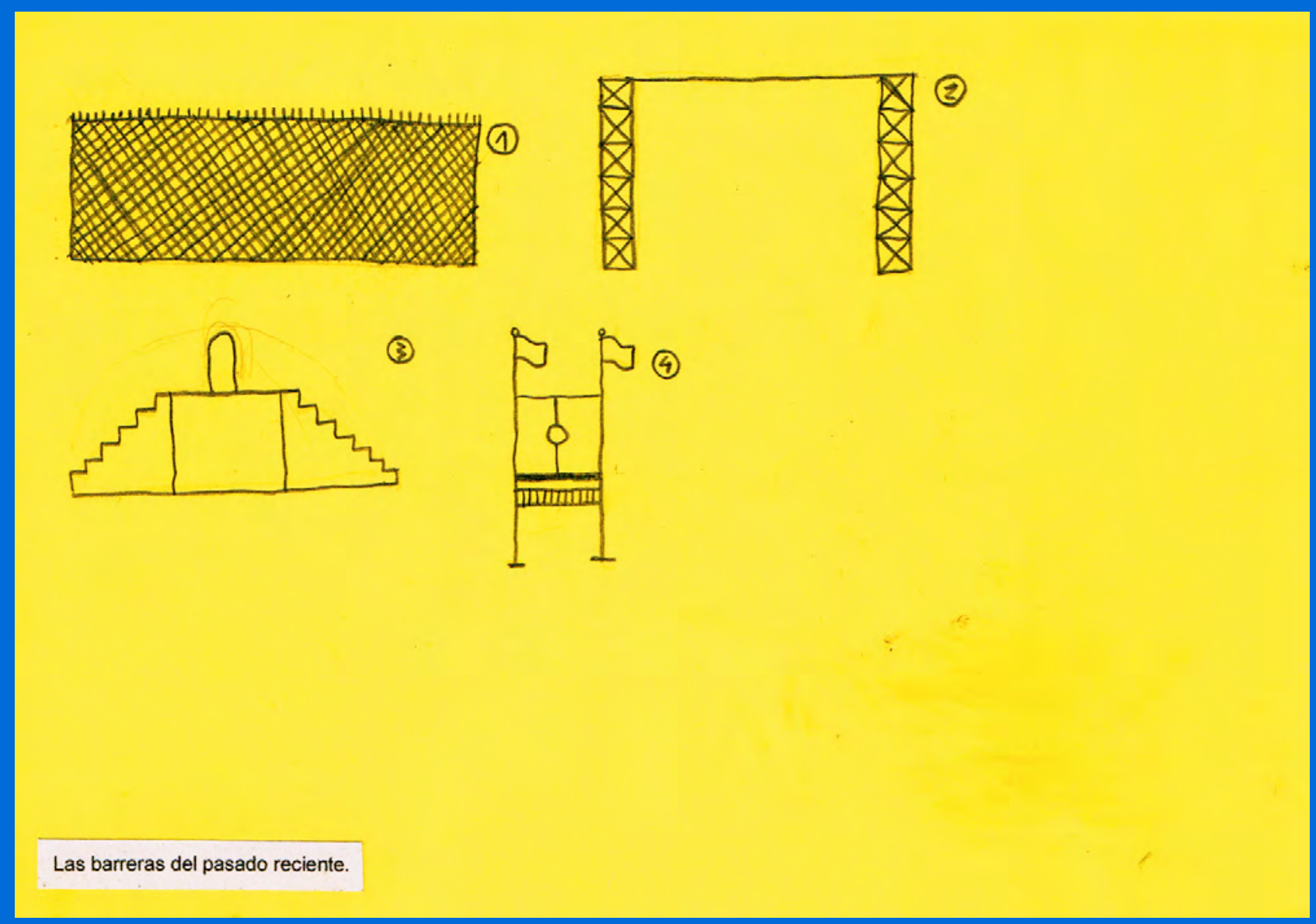

Autor: $\quad$ Rubén Gómez «Radioboy»

Título: $\quad$ "Estructuras del líder 1» (Fragmento)

Serie: «Estructuras del líder»

Año: $\quad 2015$

Técnica: $\quad$ Collage, lápiz 4B y fijador incoloro mate Soporte: $\quad$ Cartulina amarilla de $200 \mathrm{~g} / \mathrm{m}^{2}$

Dimensiones: 14,85 x $21 \mathrm{~cm}$ 


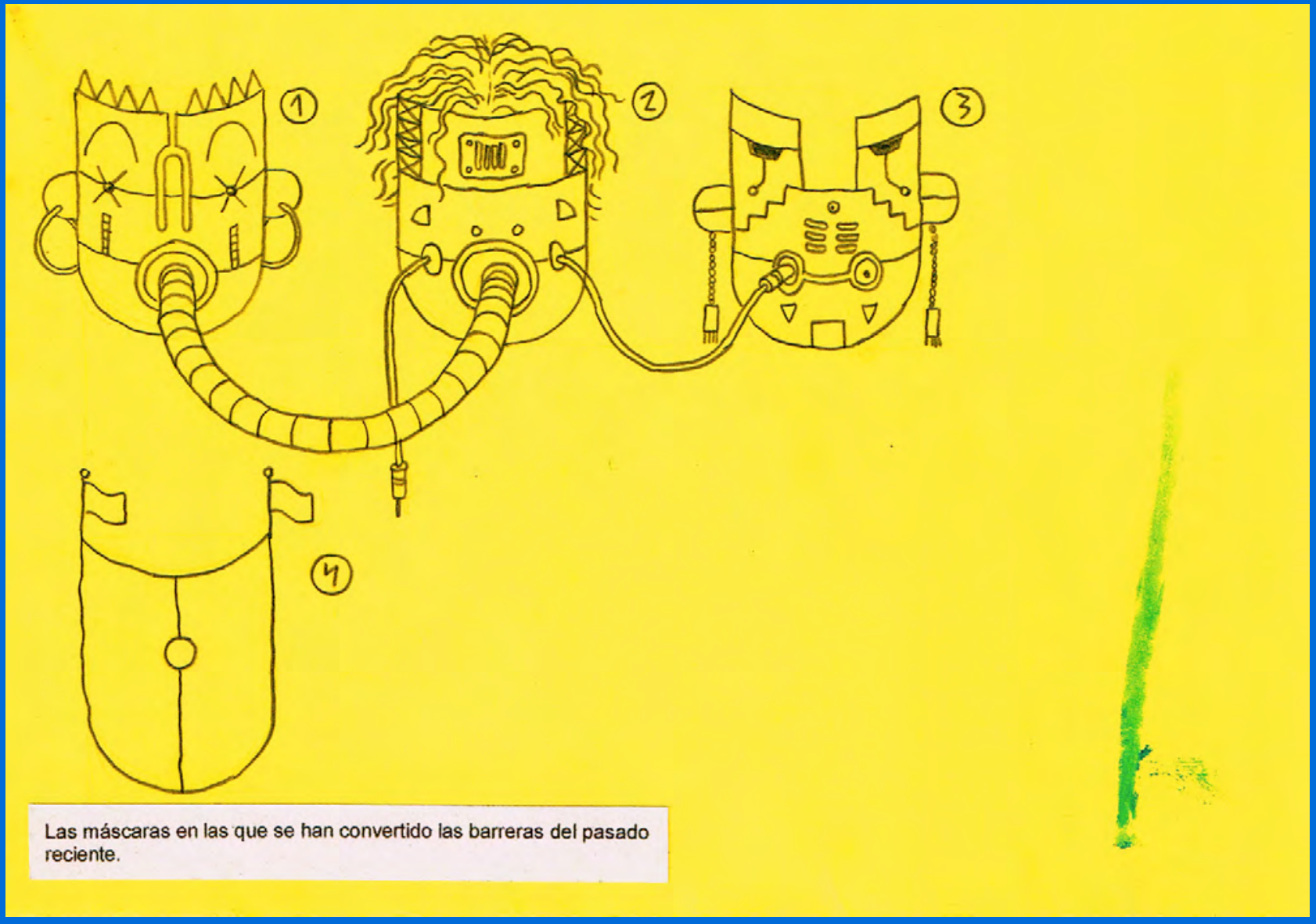

Autor: $\quad$ Rubén Gómez «Radioboy»

Título: «Estructuras del líder 1» (Fragmento)

Serie: «Estructuras del líder»

Año: $\quad 2015$

Técnica: Collage, lápiz 4B, témpera sólida verde y fijador incoloro mate Soporte: Cartulina amarilla de $200 \mathrm{~g} / \mathrm{m}^{2}$

Dimensiones: 14,85 x $21 \mathrm{~cm}$ 


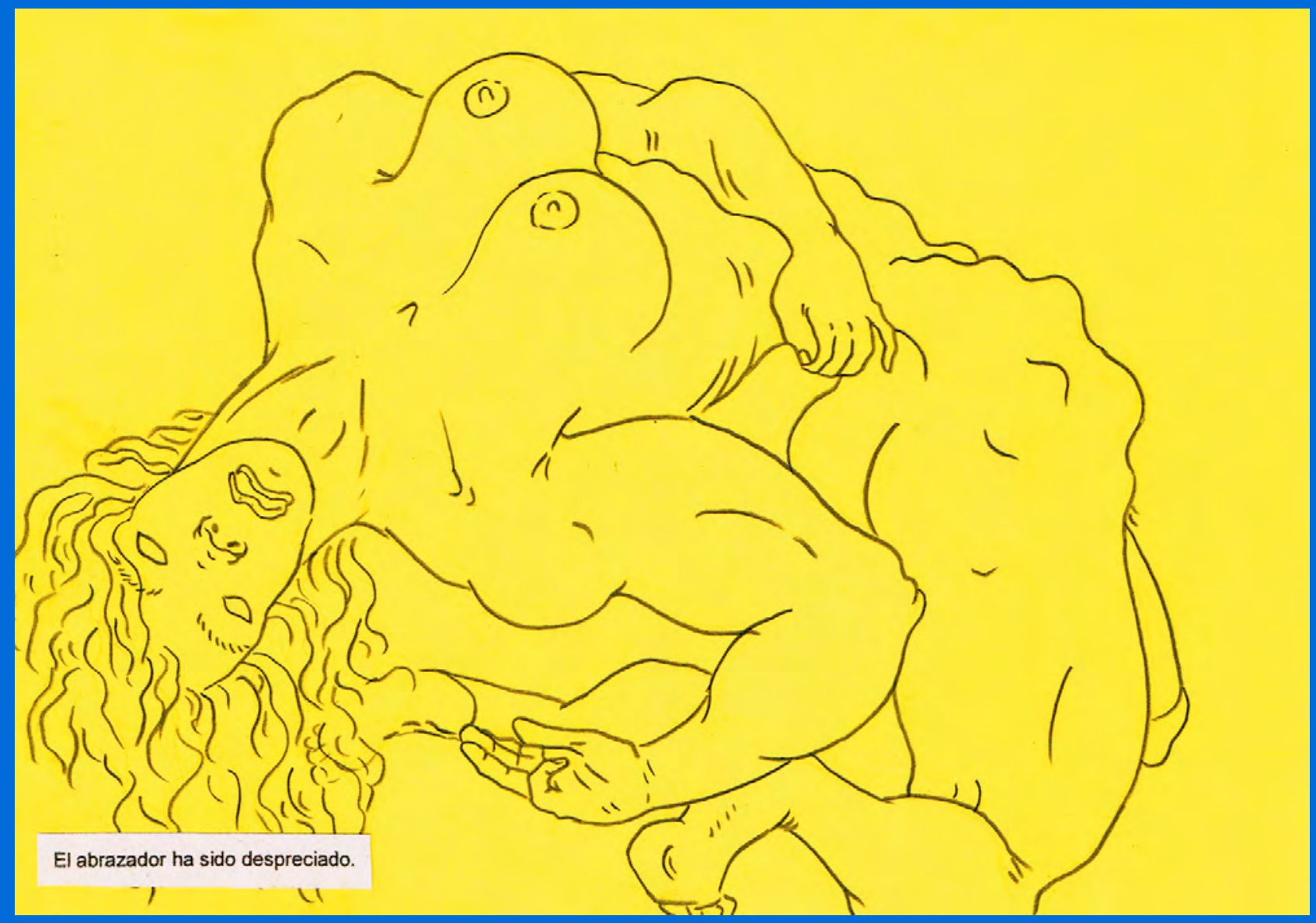

Autor: $\quad$ Rubén Gómez «Radioboy»

Título: $\quad$ "Estructuras del líder 1» (Fragmento)

Serie: $\quad$ Estructuras del líder»

Año: $\quad 2015$

Técnica: Collage, lápiz 4B y fijador incoloro mate

Soporte: Cartulina amarilla de $200 \mathrm{~g} / \mathrm{m}^{2}$

Dimensiones: 14,85 x $21 \mathrm{~cm}$ 


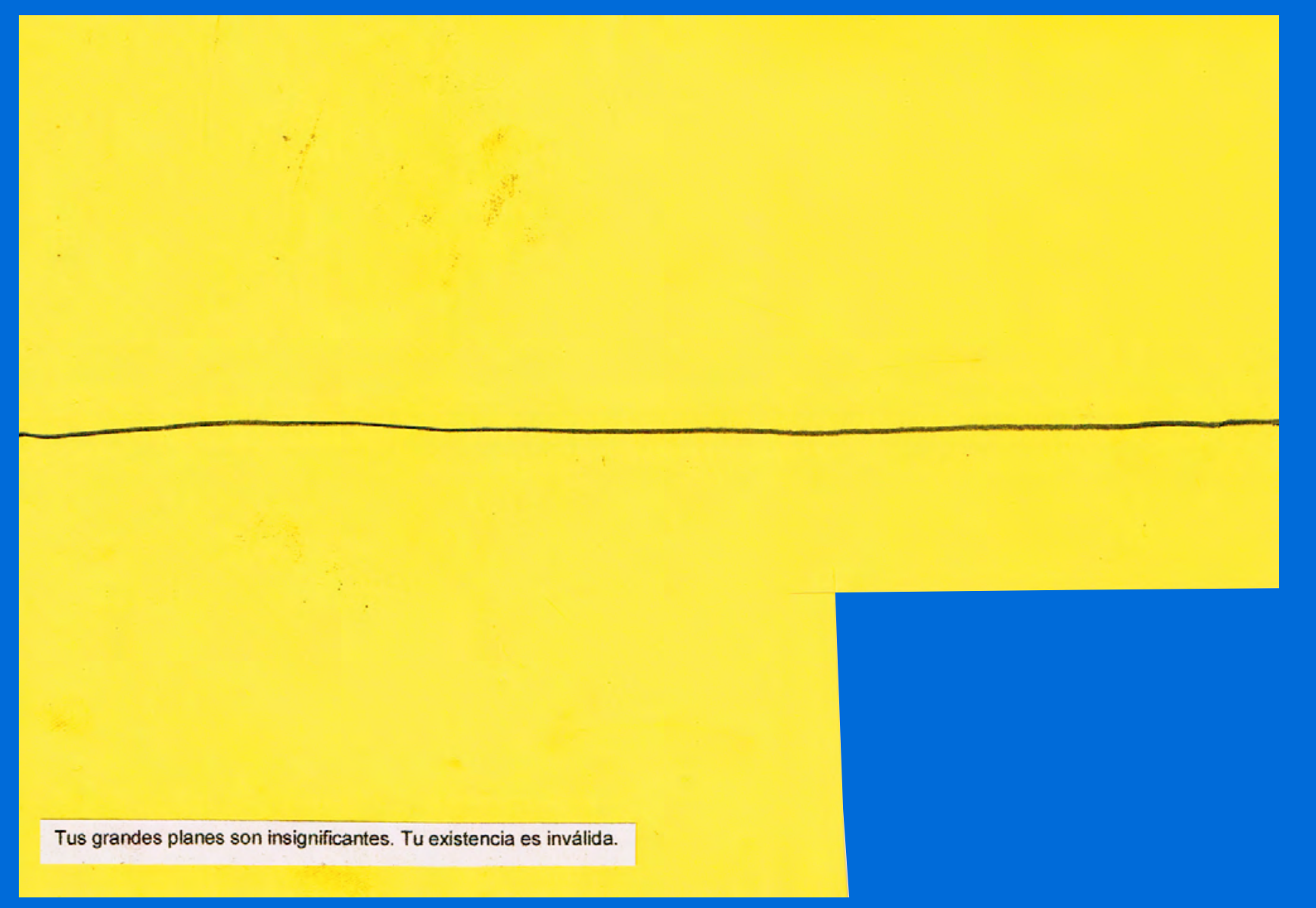
Autor: $\quad$ Rubén Gómez "Radioboy»
Título: $\quad$ "Estructuras del líder 1» (Fragmento)
Serie: $\quad$ "Estructuras del líder»
Año: $\quad 2015$
Técnica: Collage, lápiz 4B y fijador incoloro mate
Soporte: Cartulina amarilla de $200 \mathrm{~g} / \mathrm{m}^{2}$
Dimensiones: 14,85 x $21 \mathrm{~cm}$




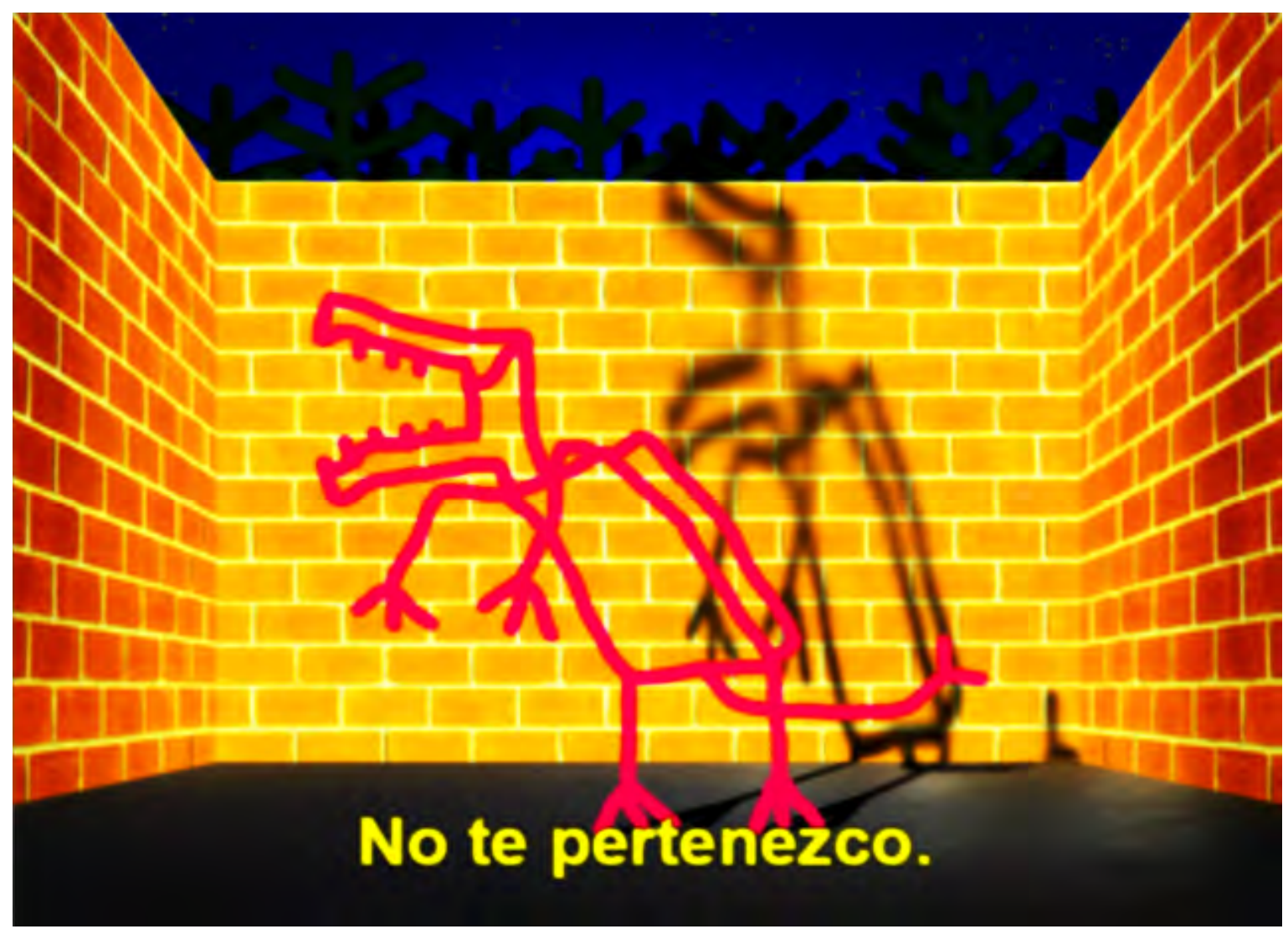

Autor: $\quad$ Rubén Gómez «Radioboy»

Título: «Escena eliminada de Estructuras del triste (2014)»

(Fotograma de vídeo)

Serie: $\quad$ "Estructuras del líder»

Año: $\quad 2016$

Técnica: Vídeo digital de animación 3D

Duración: $1 \min 12 \mathrm{~s}$

Resolución: 480 x 640 px 


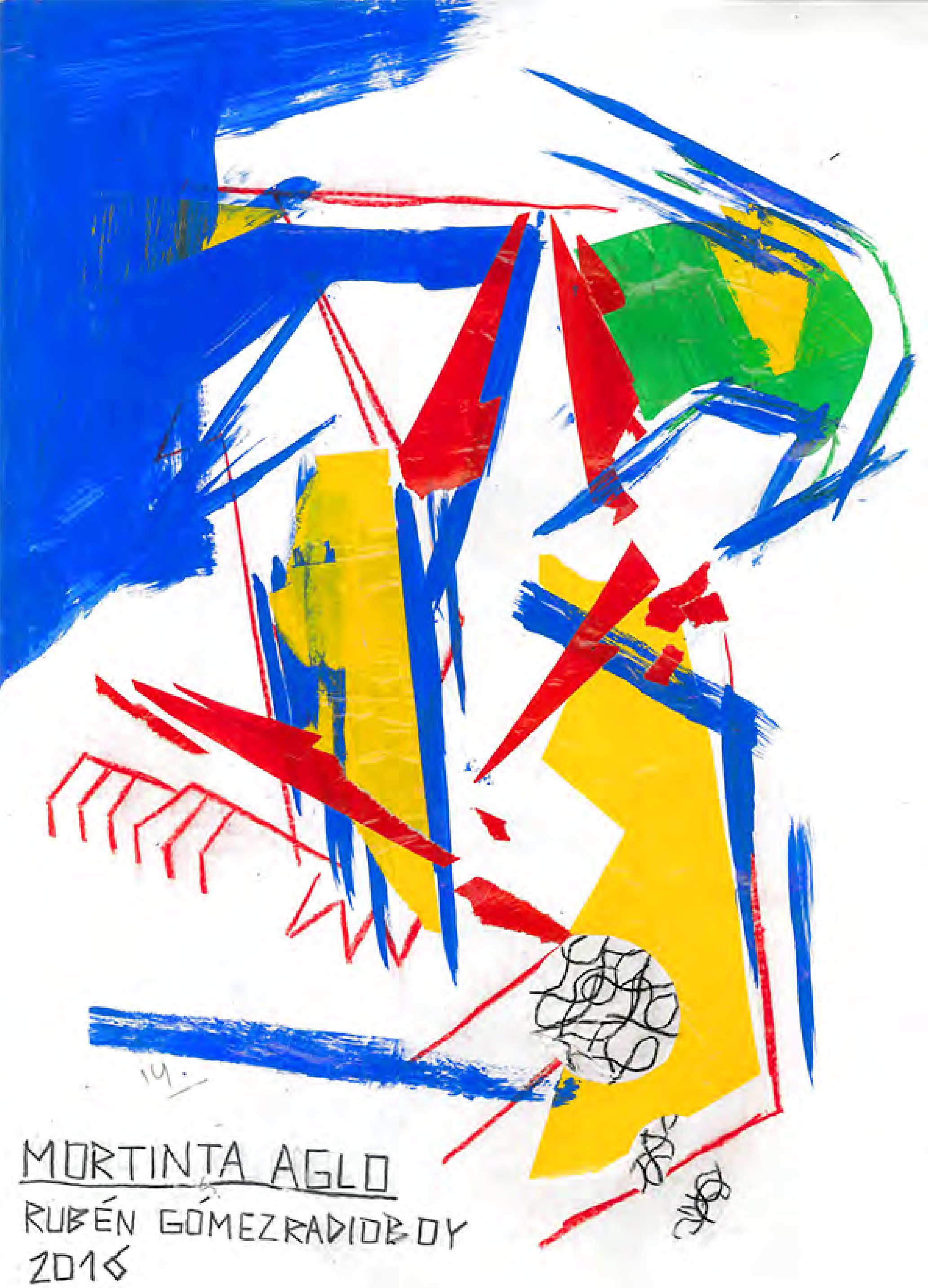




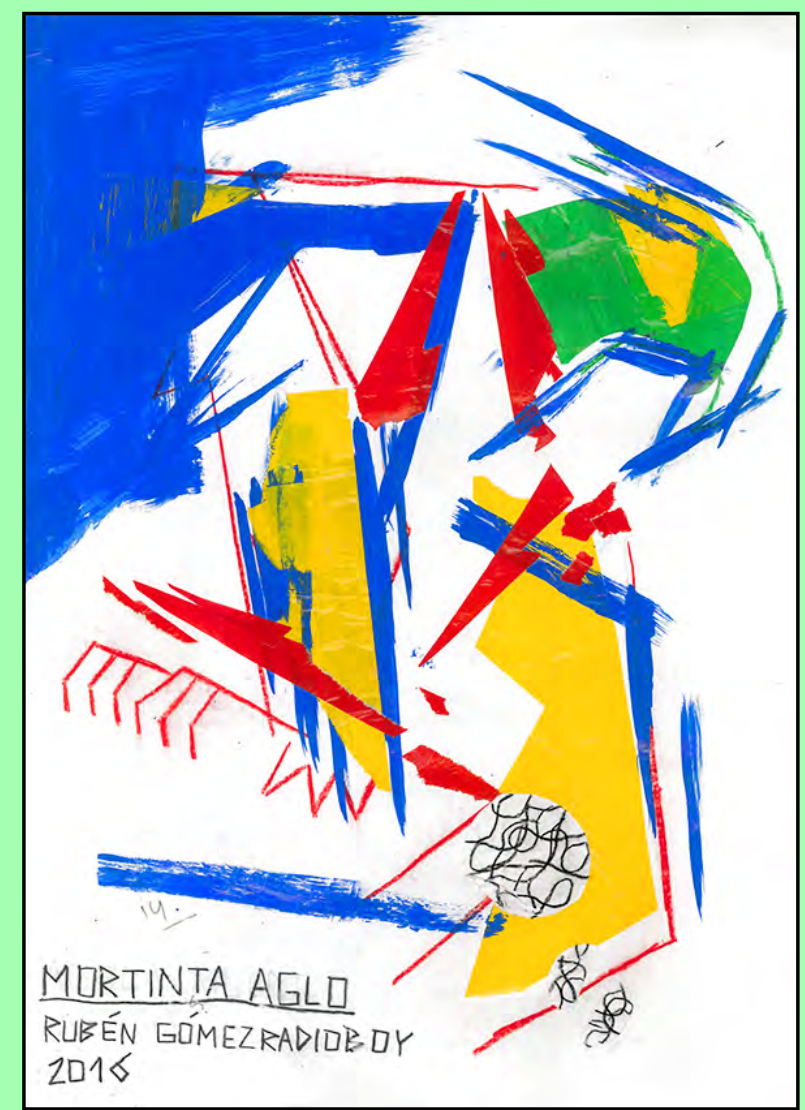

Autor: Rubén Gómez «Radioboy»

Título: $\quad$ Mortinta aglo»

Serie: «Estructuras del líder»

Año: $\quad 2016$

Técnica: Collage, lápices de colores, lápiz 6B, pintura acrílica y barniz brillante

Soporte: Cartulina blanca de $240 \mathrm{~g} / \mathrm{m}^{2}$

Dimensiones: 42 x 29,7 cm 
Datos del autor:

Nombre: Rubén Gómez «Radioboy»

Nacimiento: Alicante, 1984

Dirección: Calle Foguerer 10, 2B (03012) Alicante

Teléfono: $\quad 676789300$

E-mail: rubengomezradioboy@outlook.com

Facebook: https://www.facebook.com/rubengomezradioboy.officialfanpage

Instagram: https://www.instagram.com/rubengomezradioboy

Agradecimientos a:

José Luis Martínez Meseguer

Miguel Mesa del Castillo

Mikel Motosierra

Alex Reig

José María Torres Nadal 